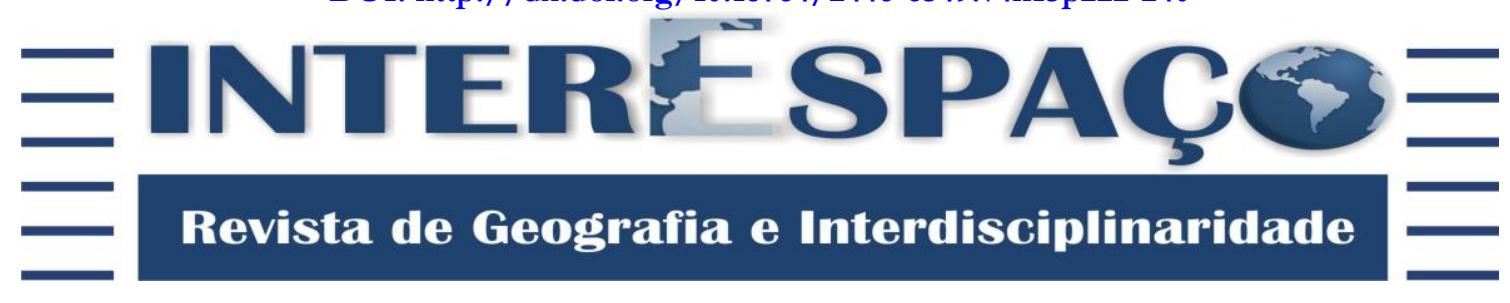

\title{
PRÁTICAS MARÍTIMAS MODERNAS NO MUNICÍPIO DE SÃO JOSÉ DE RIBAMAR - MA: ações e transformações que impulsionam o turismo local
}

PRÁCTICAS MARÍTIMAS MODERNAS EN EL MUNICIPIO DE SÃO JOSÉ DE RIBAMAR - MA: acciones y transformaciones que impulsan el turismo local

PRATIQUES MARITIMES MODERNES DANS LA MUNICIPALITÉ DE SÃO JOSÉ DE RIBAMAR - MA: actions et transformations qui animent le tourisme local

\footnotetext{
Jacilene dos Santos Castro

Mestre em Geografia pela Universidade Federal do Ceará - UFC. Graduada em Geografia pela Universidade Federal do Maranhão - UFMA. jacilene.castro@hotmail.com

Audivan Ribeiro Garcês Júnior

Doutorando em Geografia pela Universidade Federal do Ceará - UFC. Mestre em Saúde e Ambiente e Graduado em Geografia pela Universidade Federal do Maranhão - UFMA. audivanribeiro@gmail.com

\section{Paulo Roberto Mendes Pereira}

Mestre em Geografia pela Universidade Estadual Paulista "Júlio de Mesquita Filho" - UNESP/ Presidente Prudente. Graduado em Geografia pela Universidade Federal do Maranhão - UFMA. p.roberto18@hotmail.com

\section{Eustógio Wanderley Correia Dantas}

Doutor em Geografia e Planejamento - Université de Paris IV (Paris-Sorbonne). Professor Titular do Departamento de Geografia da Universidade Federal do Ceará - UFC. Vinculado ao Laboratório de Planejamento Urbano e Regional - LAPUR (Observatório das Metrópoles Núcleo Fortaleza). ewcdantas@gmail.com

Recebido para avaliação em 01/09/2018; Aprovado para publicação em 23/11/2018.

\section{RESUMO}

Ao longo dos anos evidencia-se a constante evolução no processo de apropriação do espaço e de acordo com os interesses de quem o produz são exercidas atividades que fundamentam e caracterizam cada lugar. Dentro desse contexto o espaço litorâneo tem alcançado uma grande relevância, por ser objeto de interesse que perpassa pelos campos econômicos, sociais e turísticos. Diante dessas premissas o presente artigo tem como objetivo analisar o modo como as práticas marítimas modernas vem se configurando o litoral do município de São José de Ribamar - MA. O mar ganha um novo olhar, passa a ser considerado local de descobertas e incrementos de novos modelos de apropriação. São as práticas marítimas modernas que se configuram no litoral a partir da necessidade de recriação e valorização do mesmo. Ao analisar o litoral ribamarense percebe-se que este passa por transformações que acompanham o ritmo e as necessidades de quem o usufrui. Desse modo, novos meios de apropriação do litoral vem sendo descobertos e ampliando a oferta de turismo local e podendo então, contribuir para geração de renda para o município.
} 
| Práticas marítimas modernas no município de São José de Ribamar - MA: ações e transformações que impulsionam o turismo local|

|Jacilene dos Santos Castro | Audivan Ribeiro Garcês Júnior | Paulo Roberto Mendes Pereira| | Eustógio Wanderley Correia Dantas |

Palavras-chave: Litoral; Práticas Marítimas; Reconfiguração.

\section{RESUMEN}

A lo largo de los años se evidencia la constante evolución en el proceso de apropiación del espacio y de acuerdo con los intereses de quien lo produce son ejercidas actividades que fundamentan y caracterizan cada lugar. Dentro de ese contexto el espacio costero ha alcanzado una gran relevancia, por ser objeto de interés que atraviesa por los campos económicos, sociales y turísticos. Ante estas premisas el presente artículo tiene como objetivo analizar el modo como las prácticas marítimas modernas vienen configurando el litoral del municipio de São José de Ribamar - MA. El mar gana una nueva mirada, pasa a ser considerado lugar de descubrimientos e incrementos de nuevos modelos de apropiación. Son las prácticas marítimas modernas que se configuran en el litoral a partir de la necesidad de recreación y valorización del mismo. Al analizar el litoral ribamarense percibimos que lo mismo pasa por transformaciones que acompañan el ritmo y las necesidades de quien lo disfruta. De este modo, nuevos medios de apropiación del litoral han sido descubiertos y ampliando la oferta de turismo local y contribuyendo para generación de ingresos sea formal o informal.

Palabras clave: Litoral; Prácticas Marítimas; Reconfiguración.

\section{RÉSUMÉ}

Au fil des ans, l'évolution constante du processus d'appropriation de l'espace est évidente et, selon les intérêts de ceux qui la produisent, sont menées des activités qui fondent et caractérisent chaque lieu. Dans ce contexte, la zone côtière a atteint une grande importance, étant un objet d'intérêt qui traverse les domaines économique, social et touristique. Au vu de ces prémisses, cet article vise à analyser comment les pratiques maritimes modernes ont façonné la côte de la commune de. La mer fait peau neuve, elle devient un lieu de découvertes et d'incréments de nouveaux modèles d'appropriation. Ce sont les pratiques maritimes modernes qui sont configurées sur la côte du besoin de le recréer et de l'améliorer. Lors de l'analyse de la côte ribamarienne, nous percevons qu'il en va de même pour les transformations qui suivent le rythme et les besoins de ceux qui les apprécient. Ainsi, de nouveaux moyens d'appropriation du littoral sont découverts et élargissent l'offre de tourisme local et contribuent à la création de revenus, qu'ils soient formels ou informels.

Mots-clés: Coastal; Pratiques Maritimes; Reconfiguration.

\section{INTRODUÇÃO}

O litoral, desde a época colonial, sempre foi considerado como um espaço privilegiado seja por sua importância no processo de ocupação do continente ou por ser um ponto estratégico de entrada e saída de mercadorias. O que liga o litoral ao mundo externo, ao mesmo tempo em que estabelece relações diretas com o continente. Essa área litorânea que passa a ser ocupada tem em sua população e suas atividades, características peculiares aos espaços marinhos. São práticas marítimas tradicionais que nascem junto à ocupação: criação de portos, para entrada e saída de mercadorias, construção de fortes a fim de proteger a área conquistada, e pesca artesanal, principal fonte de alimentação e renda.

O século XIX tem como marco o início das transformações que se inserem no litoral. Com as inovações tecnológicas, as navegações a vapor passam a dar um novo ritmo 
|Práticas marítimas modernas no município de São José de Ribamar - MA: ações e transformações que impulsionam o turismo local|

|Jacilene dos Santos Castro | Audivan Ribeiro Garcês Júnior | Paulo Roberto Mendes Pereira | | Eustógio Wanderley Correia Dantas |

às cidades litorâneas, o que acaba corroborando com uma nova organização do espaço. Segundo Dantas (2010, p. 45), "no final do século XIX, início do século XX, no cerne do desejo pelo mar, dá-se a implementação das práticas marítimas modernas no Brasil pela elite", cuja atração pelo mar se findava na importância do banho de mar como uma prática curativa e de lazer.

O banho de mar no Brasil iniciou-se de forma tímida, com uma pequena parcela da elite desfrutando dos benefícios terapêuticos trazidos pelo mar (doenças pulmonares, estresse...), alegados pelos discursos médicos da época. A partir disso, com a consolidação dos tratamentos terapêuticos e com a construção de rodovias que ligavam o centro das cidades às áreas litorâneas, essa elite começa a construir sua segunda residência no litoral, onde o maior fluxo era nos fins de semana e em dias quentes, essas são as chamadas casas de veraneio (DANTAS, 2010, p. 47).

Essa dinâmica de se deslocar e usufruir do litoral para diversos fins caracteriza-se como vilegiatura marítima. Vilegiatura também pode ser compreendida como:

\begin{abstract}
A atividade de lazer na qual um indivíduo ou determinado grupo utiliza, em regime sazonal, de outro domicílio próprio, diferente do domić́lio utilizado em seu cotidiano. Ela implica em deslocamento voluntário, em busca de descanso, ócio e/ou o desenvolvimento de práticas de lazer. Para tanto, torna-se indispensável a posse de recursos suficientes para administrar um domicílio adicional, o pagamento de um caseiro, e as despesas decorrentes (DE PAULA, 2010, p. 4).
\end{abstract}

Tais práticas podem ser confirmadas por Dantas (2010, p. 23), onde relata o processo de vilegiaturismo em cidades como Rio de Janeiro, que em 1892 as praias são tomadas por residências secundárias. Fortaleza, em 1930, as casas de veraneios dão suporte ao tratamento de doenças pulmonares e Recife, em 1950, onde relata a sazonalidade da ocupação das segundas residências.

Mais recentemente o litoral abriu espaço para o turismo litorâneo. A região Nordeste do Brasil se destaca como principal destino para o turismo no país, e a atividade passa a constituir uma das principais bases econômicas dessa região. Teoria afirmada a partir da "lógica de valorização alicerçada pelo PRODETUR-NE a partir do final do século XX (anos 1980-1990)" (DANTAS, 2010, p. 48). Tais investimentos inseridos no litoral através de programas do governo e de políticas públicas voltadas para valorização do espaço focaram novos olhares para as cidades litorâneas, o olhar turístico.

O volume de investimentos lançados ao turismo litorâneo fez com essa região fosse considerada uma das mais rentáveis economicamente. O que também lançou mão de 
| Práticas marítimas modernas no município de São José de Ribamar - MA: ações e transformações que impulsionam o turismo local|

|Jacilene dos Santos Castro | Audivan Ribeiro Garcês Júnior | Paulo Roberto Mendes Pereira| |Eustógio Wanderley Correia Dantas |

políticas voltadas para as áreas que não faziam parte da zona litoral, havendo assim uma concentração de recursos nas áreas consideradas de interesse econômico.

No Maranhão, é a partir da década de 1960 que novos olhares são lançados para o litoral, com a criação de órgãos estaduais dedicados ao planejamento do turismo. Porém, segundo Costa (2017, p. 58), é somente em meados da década de 1990 que a expansão do turismo se dá no litoral do estado a partir do eixo São Luís-Alcântara e que se estende, após, para a área do Parque Nacional dos Lençóis Maranhenses e seu entorno.

Cabe salientar que a maior parte dos municípios do litoral do Maranhão tem como principal forma de uso e ocupação as atividades do setor primário (pesca e agricultura). No contexto atual, a dinâmica de apropriação do litoral abre espaço para novas formas de uso, seja pela exploração mineral, geração de energia eólica, além de instalação de novas infraestruturas como casas de veraneio, pousadas, bares e restaurantes, o que impulsiona o turismo para a região. Neste sentido, esta pesquisa busca analisar o modo como as práticas marítimas modernas vêm se configurando no litoral do município de São José de Ribamar, no estado do Maranhão.

O município de São José de Ribamar está situado na porção oriental da Ilha do Maranhão, fazendo parte da Mesorregião Norte Maranhense e juntamente com os municípios de São Luís, Raposa e Paço do Lumiar, pertence à Microrregião denominada de Aglomeração Urbana de São Luís. Sua sede encontra-se a $30 \mathrm{~km}$ de São Luís, capital do Maranhão, e está ligada pelas rodovias estaduais MA 201, 202 e 203, que conectam respectivamente os municípios de São Luís, Paço do Lumiar e Raposa (FONSECA, 2013). Localiza-se geograficamente a $2^{\circ} 33^{\prime} 43^{\prime \prime}$ de latitude sul e $44^{\circ} 03^{\prime} 15^{\prime \prime}$ de longitude oeste. Detém uma extensão territorial de $388,371 \mathrm{~km}^{2}$, onde segundo o IBGE (2010) é o centésimo vigésimo primeiro município em extensão territorial do Maranhão, ocupando assim uma área total de $0,13 \%$ do estado. Limita-se ao norte com o Oceano Atlântico e com o município de Paço do Lumiar, ao leste e ao sul com a baía de São José, e a oeste com o município de São Luís (Figura 1). 
| Práticas marítimas modernas no município de São José de Ribamar - MA: ações e transformações que impulsionam o turismo local|

|Jacilene dos Santos Castro | Audivan Ribeiro Garcês Júnior | Paulo Roberto Mendes Pereira| |Eustógio Wanderley Correia Dantas |

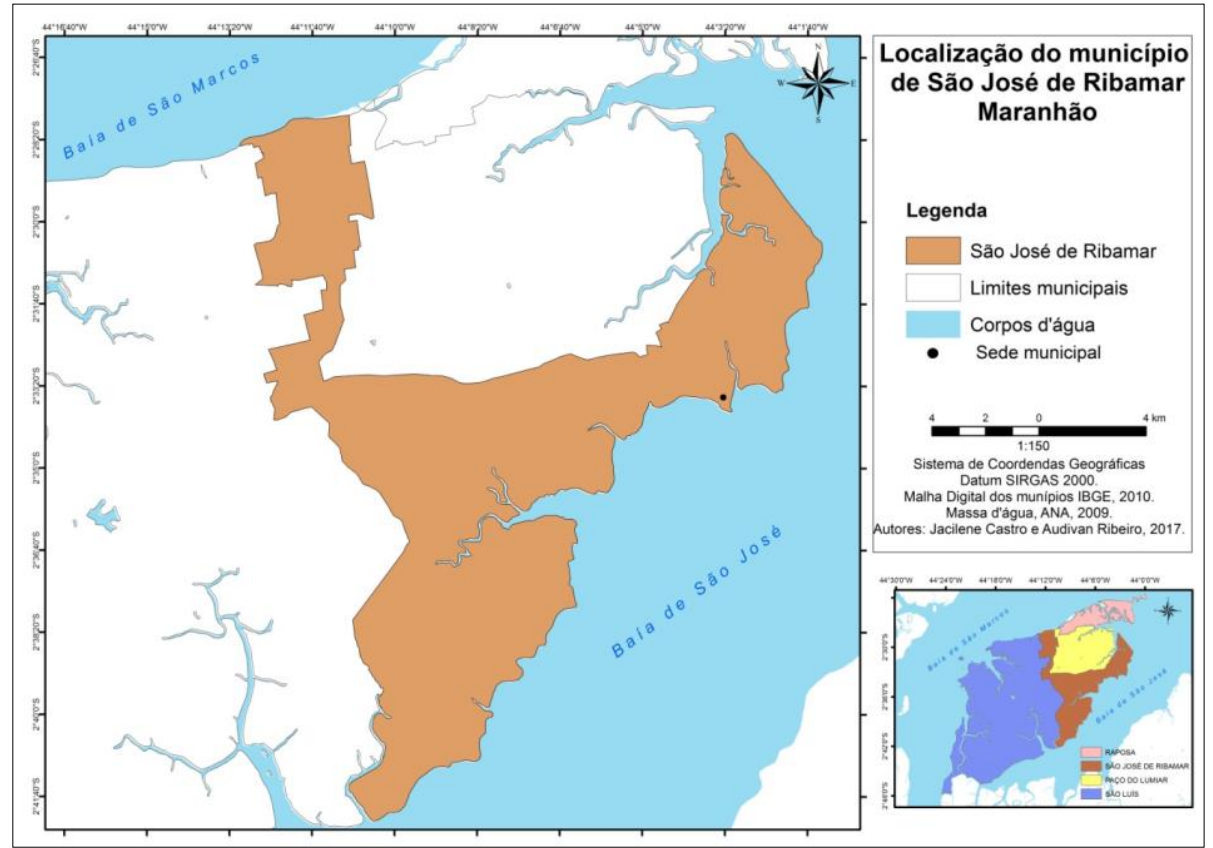

Figura 1 - Localização do município de São José de Ribamar - MA.

Fonte: IBGE, 2010. Organizado pelos autores.

\section{PRÁTICAS MARÍTIMAS MODERNAS NO MUNICÍPIO DE SÃO JOSÉ DE RIBAMAR}

O município de São José de Ribamar é tradicionalmente conhecido pela oferta do turismo religioso. Porém, com o incremento de novas políticas voltadas para a valorização do litoral, o mesmo começa a ganhar destaque no setor turístico através de atividades relacionadas à maritimidade. São vários os fatores que atraem o público para essa atividade, o principal deles é a combinação de calor, água e diversão. São José de Ribamar dispõe de atrativos naturais que atraem turistas e visitantes que buscam lazer e bem-estar, são as praias urbanas e praias semidesertas (Figura 2). 
| Práticas marítimas modernas no município de São José de Ribamar - MA: ações e transformações que impulsionam o turismo local|

|Jacilene dos Santos Castro | Audivan Ribeiro Garcês Júnior | Paulo Roberto Mendes Pereira | |Eustógio Wanderley Correia Dantas |

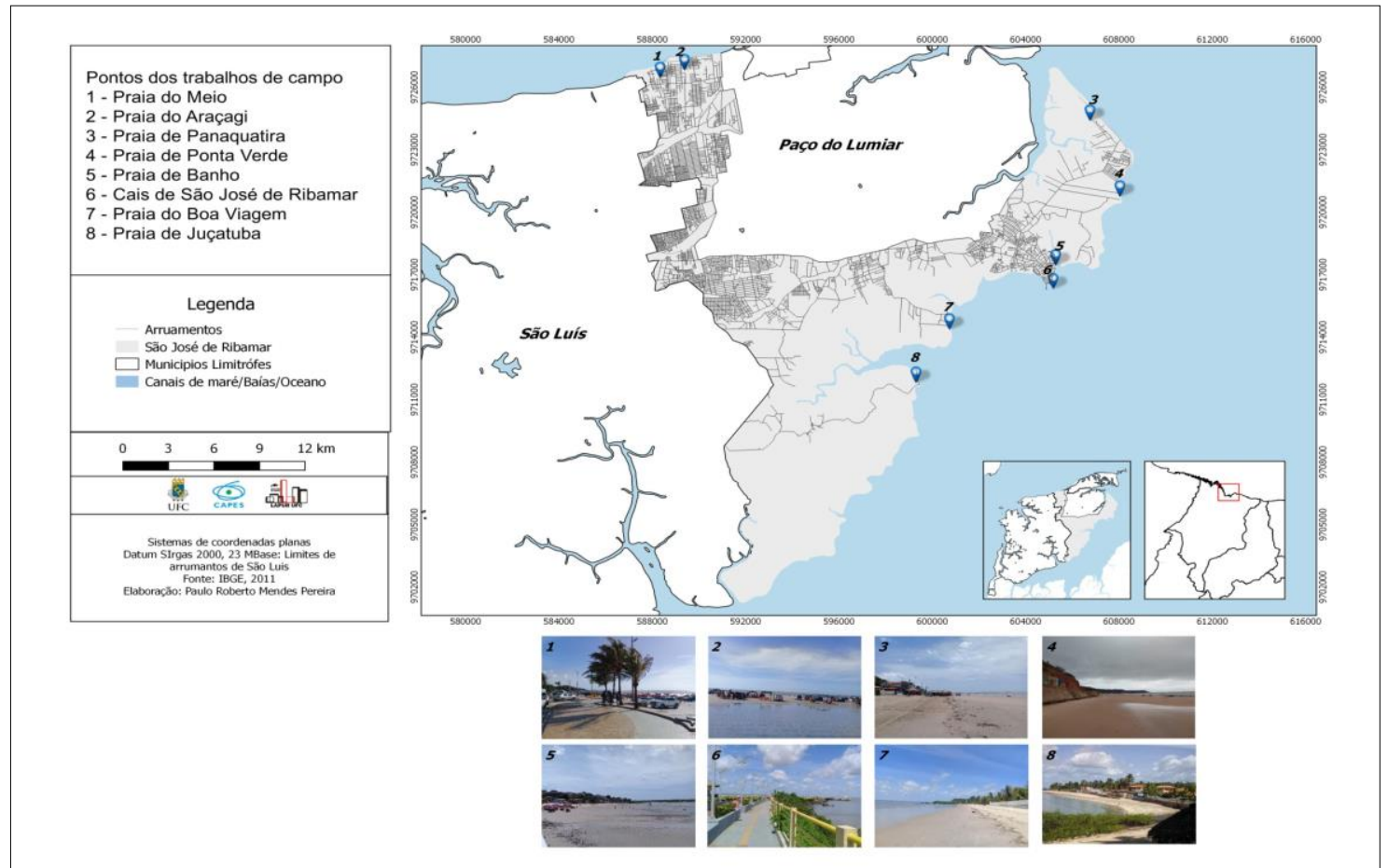

Figura 2 - Localização das praias de São José de Ribamar - MA. Fonte: Elaborado pelos autores.

Dentre as praias urbanas, destaca-se: a Praia de Banho, localizada na região central de São José de Ribamar. A Praia de Panaquatira, considerada uma das melhores do município em relação à balneabilidade. Praias do Meio e Araçagy são praias mais movimentadas e dispõem de infraestruturas modernas, que vão desde a modernização de sua orla a instalações de bares, restaurantes e lojas.

Algumas praias de São José de Ribamar são ideais para a realização de camping, por serem áreas menos povoadas e consequentemente possuir um fluxo menor de pessoas, dentre elas as praias de Juçatuba e Boa Viagem, consideradas semidesertas, por serem isoladas, devido ao seu difícil acesso. Além das praias do Caúra e Ponta Verde que são praias formadas por falésias, são propícias para esportes náuticos e com casas de veraneio, disponibilizadas para aluguel.

Em se tratando de economia, no município de São José de Ribamar, as principais atividades econômicas que se destacam estão centradas no setor primário: a pesca artesanal, grande potencial econômico local, agricultura de subsistência. O município também desenvolve atividades nos setores secundário e terciário, atividades importantes como o comércio, essencialmente varejista de gêneros alimentícios e de medicamentos, porém tendo como fator inibidor de expansão a proximidade com a capital, em virtude de muitos produtos serem adquiridos em São Luís, principalmente no que se refere à aquisição de bens duráveis e vestuários. $O$ artesanato também é um potencial econômico e 
|Práticas marítimas modernas no município de São José de Ribamar - MA: ações e transformações que impulsionam o turismo local|

|Jacilene dos Santos Castro | Audivan Ribeiro Garcês Júnior | Paulo Roberto Mendes Pereira | |Eustógio Wanderley Correia Dantas |

representativo do município, além do turismo que constitui expressiva fonte de renda para a economia municipal, em virtude de São José de Ribamar ser uma cidade litorânea e ter uma forte tradição religiosa e cultural.

Dentre os novos usos do litoral, podemos destacar as praias urbanas do município, dentre elas a Praia de Banho (Figura 3), onde em sua orla acontece a maioria dos eventos, é a mais acessível, pois fica no centro da cidade.

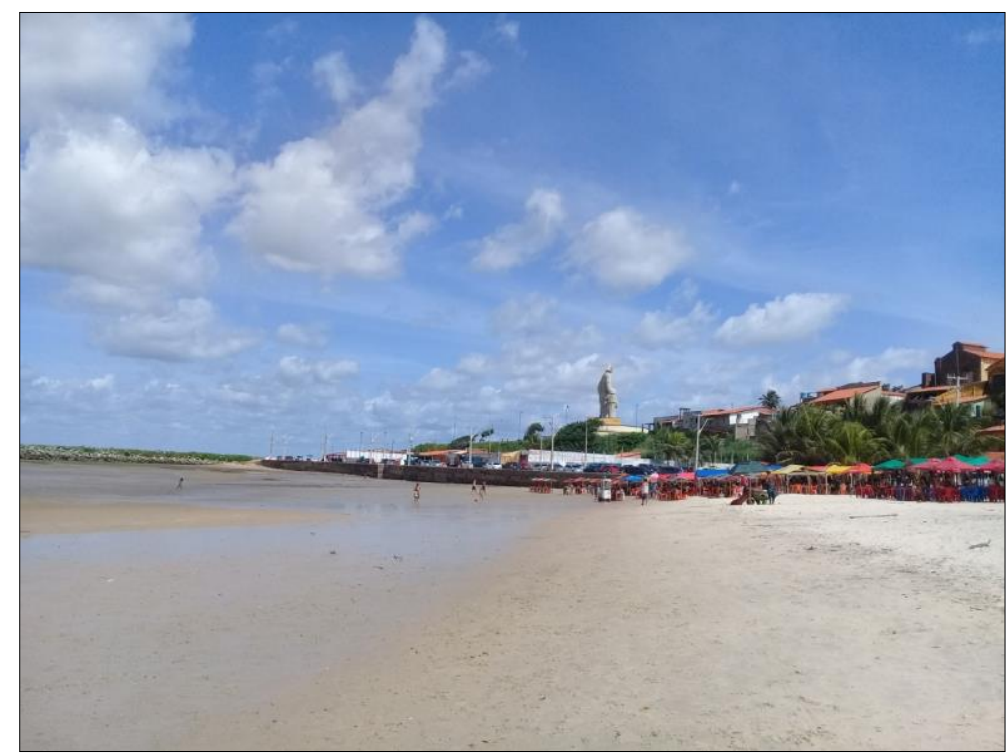

Figura 3 - Praia de Banho. Vista voltada para a sede da cidade. Fonte: Registro dos autores, 2018.

Nela encontram-se residências, bares e restaurantes bastante frequentados aos finais da semana. Grandes eventos também acontecem na orla da Praia de Banho, dentre eles o Carnaval "Lava Pratos", que é o carnaval fora de época da cidade e o Lava Bois. A praia de banho recebe uma grande quantidade de turistas na mesma época, sua demanda é principalmente pelo turismo de massa, haja vista que sua reestruturação foi pensada como forma de receber um grande quantitativo de pessoas e eventos de grande proporção.

Já a praia de Panaquatira (Figura 4) recebe intensa influência das marés, alargandose por vários quilômetros quando a maré está baixa, tornando-se ideal para passeios e caminhadas. Há facilidade de acesso devido ao asfaltamento da única via de acesso à praia. 
| Práticas marítimas modernas no município de São José de Ribamar - MA: ações e transformações que impulsionam o turismo local|

|Jacilene dos Santos Castro | Audivan Ribeiro Garcês Júnior | Paulo Roberto Mendes Pereira | | Eustógio Wanderley Correia Dantas |

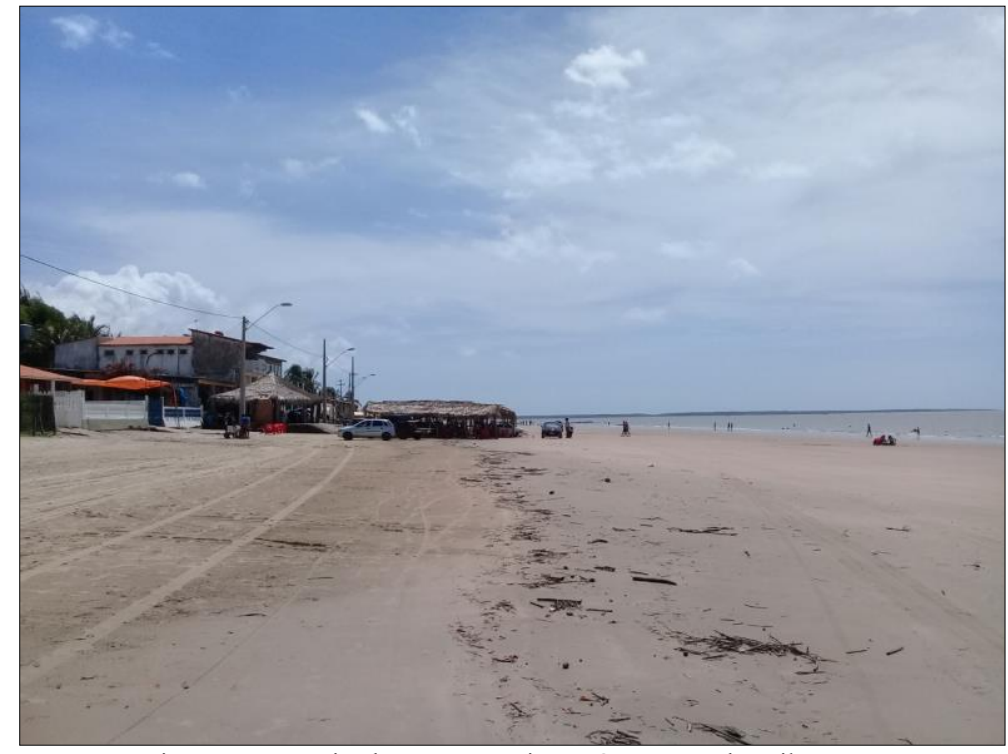

Figura 4 - Praia de Panaquatira - São Jose de Ribamar. Fonte: Registro dos autores, 2018.

Uma das características da praia de Panaquatira é a grande quantidade de casas de veraneio, onde parte encontra-se disponível para locação por temporada. Hoje percebemos que essas segundas residências começam a ser pouco frequentadas por seus proprietários, devido ao aumento da violência na região ${ }^{1}$, por isso o aluguel temporário é uma opção para muitos proprietários (Figura 5).

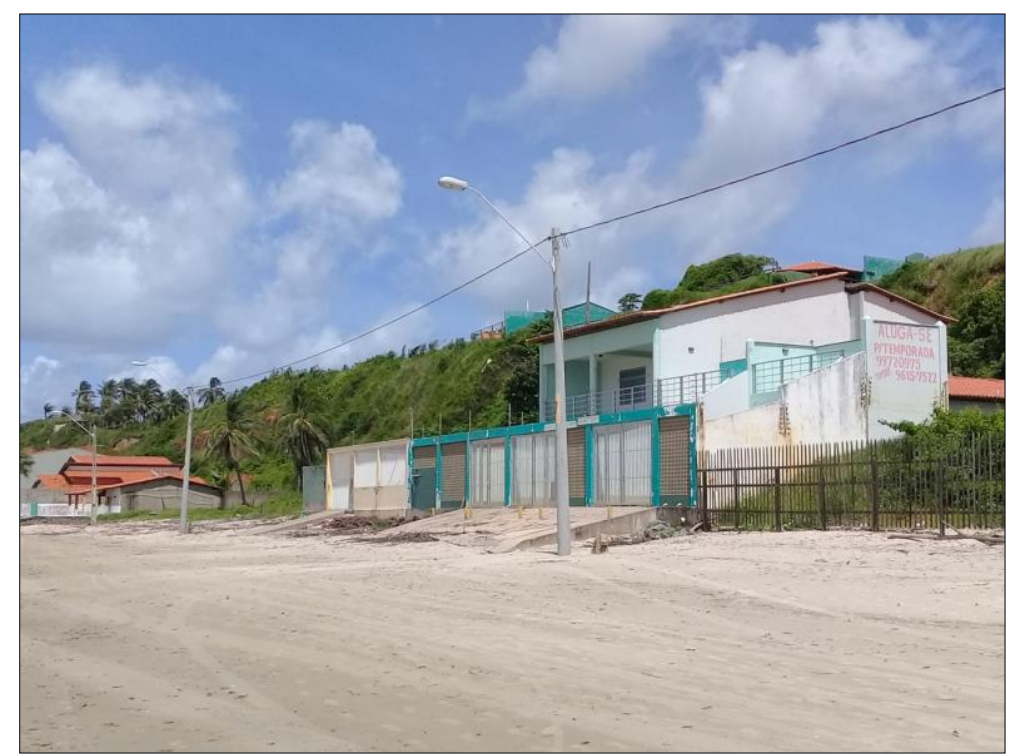

Figura 5 - Casas de Veraneio na Praia de Panaquatira - São Jose de Ribamar.

Fonte: Registro dos autores, 2018.

\footnotetext{
${ }^{1}$ Com base no Atlas da Violência, elaborado pelo Instituto de Pesquisa Econômica e Aplicada (IPEA), São José de Ribamar é o município, com mais de 100 mil habitantes, mais violento do Maranhão e o $4^{\circ}$ do Brasil, considerando as taxas de homicídios (IPEA, 2017).
} 
| Práticas marítimas modernas no município de São José de Ribamar - MA: ações e transformações que impulsionam o turismo local|

|Jacilene dos Santos Castro | Audivan Ribeiro Garcês Júnior | Paulo Roberto Mendes Pereira | |Eustógio Wanderley Correia Dantas |

Apesar do índice de violência ter aumentado na região, Panaquatira é uma das praias mais procuradas pela população da região metropolitana, principalmente de São Luís, que buscam fugir do intenso aglomerado das praias da capital. $\mathrm{Na}$ orla de Panaquatira, bares e restaurantes ofertam variados cardápios, com prioridades para os frutos do mar. Além de vendedores ambulantes que buscam a ampliação de sua renda, são em sua maioria vendedores de água de coco e artesanatos em geral.

Com um considerável fluxo de pessoas, as praias do Meio (Figura 6) e Araçagy (Figura 7), que ficam próximas a São Luís, nos fins de semanas, têm grande movimentação de turistas e banhistas da capital.

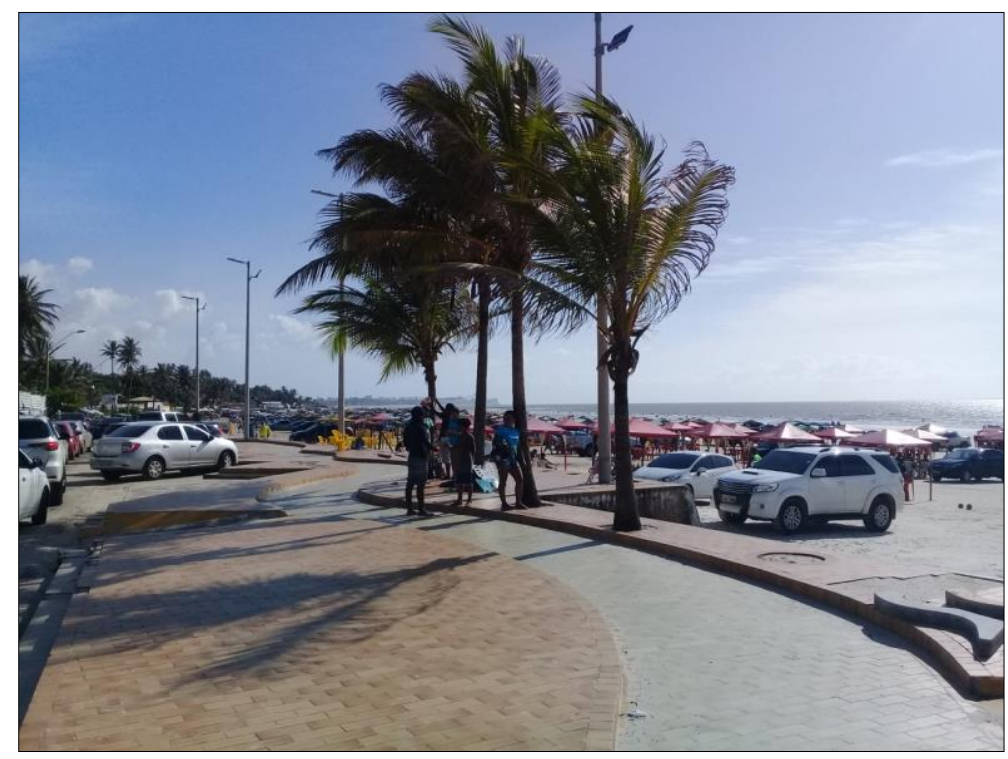

Figura 6 - Praia do Meio - São Jose de Ribamar.

Fonte: Registro dos autores, 2018.

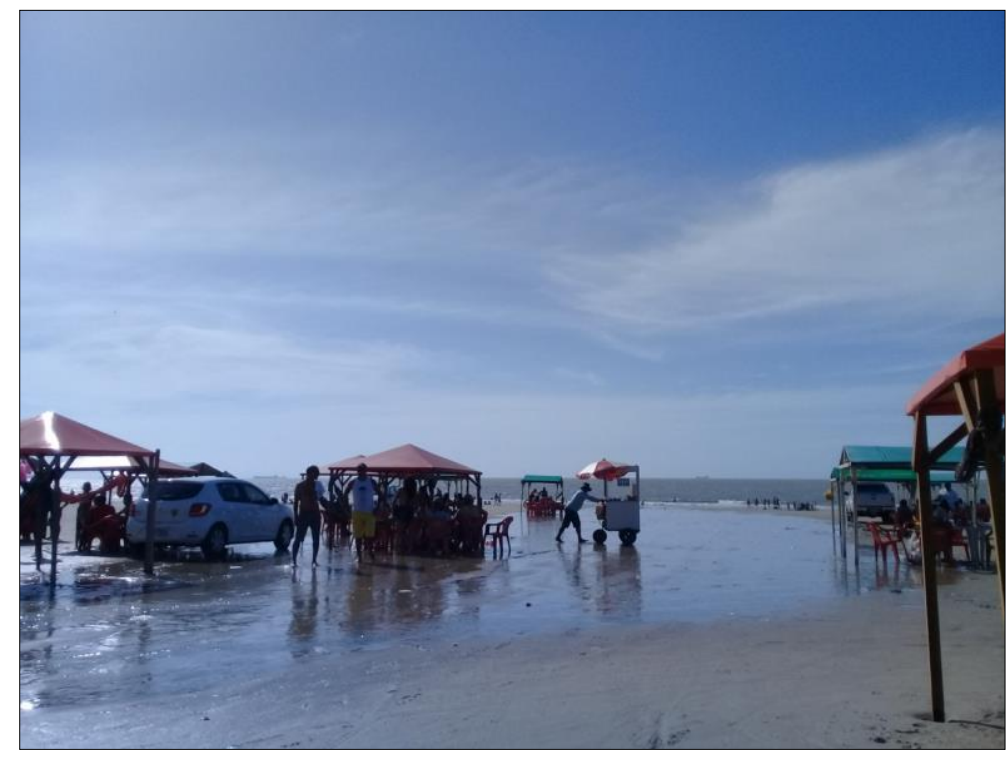

Figura 7 - Praia do Araçagy - São Jose de Ribamar.

Fonte: Registro dos autores, 2018. 
| Práticas marítimas modernas no município de São José de Ribamar - MA: ações e transformações que impulsionam o turismo local|

|Jacilene dos Santos Castro | Audivan Ribeiro Garcês Júnior | Paulo Roberto Mendes Pereira | |Eustógio Wanderley Correia Dantas |

São praias com características semelhantes, urbanizadas, com calçamento reservado para caminhada e implantação de quiosques e com grande fluxo de pessoas. Essa porção do litoral dispõe diversas atividades que incluem esportes náuticos como kitesurf (Figura 8), caminhada pela orla e vilegiatura.

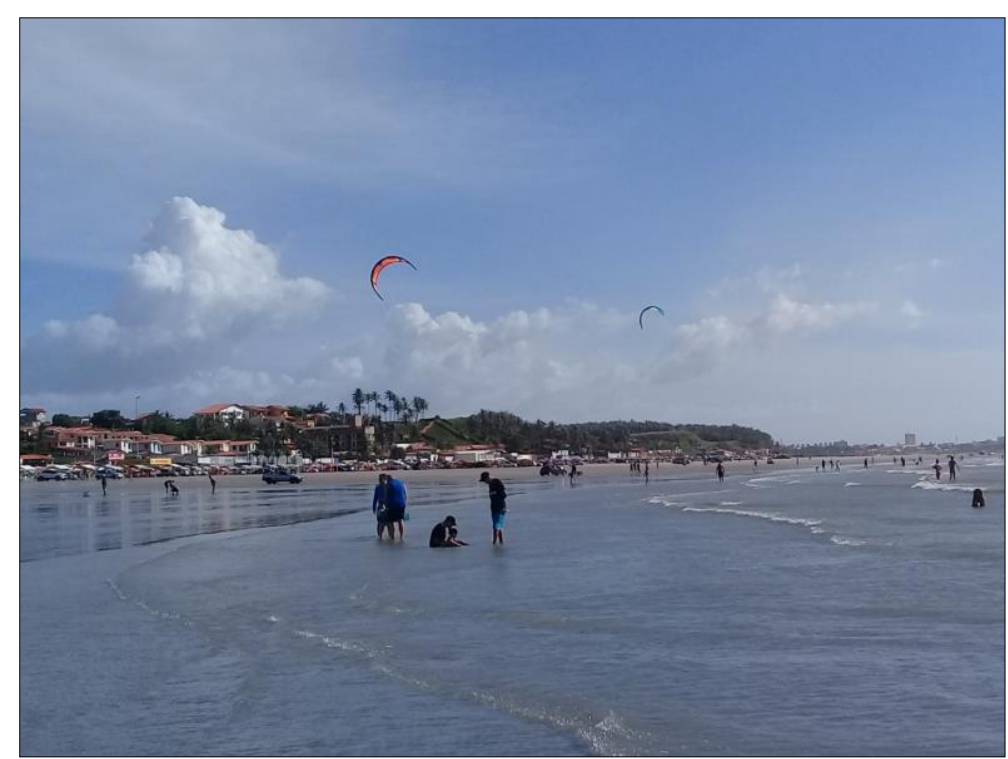

Figura 8 - Kitesurf praticado na praia do Meio - São Jose de Ribamar. Fonte: Registro dos autores, 2018.

A praia do Araçagy dispõe hoje de parte de sua orla revitalizada (Figura 9), com a pavimentação da Av. Atlanta, embora ainda não finalizada, é perceptível a mudança que ocorreu no trecho revitalizado. O local virou um ponto turístico e de lazer da região e vendedores já começam a explorar essa nova área.

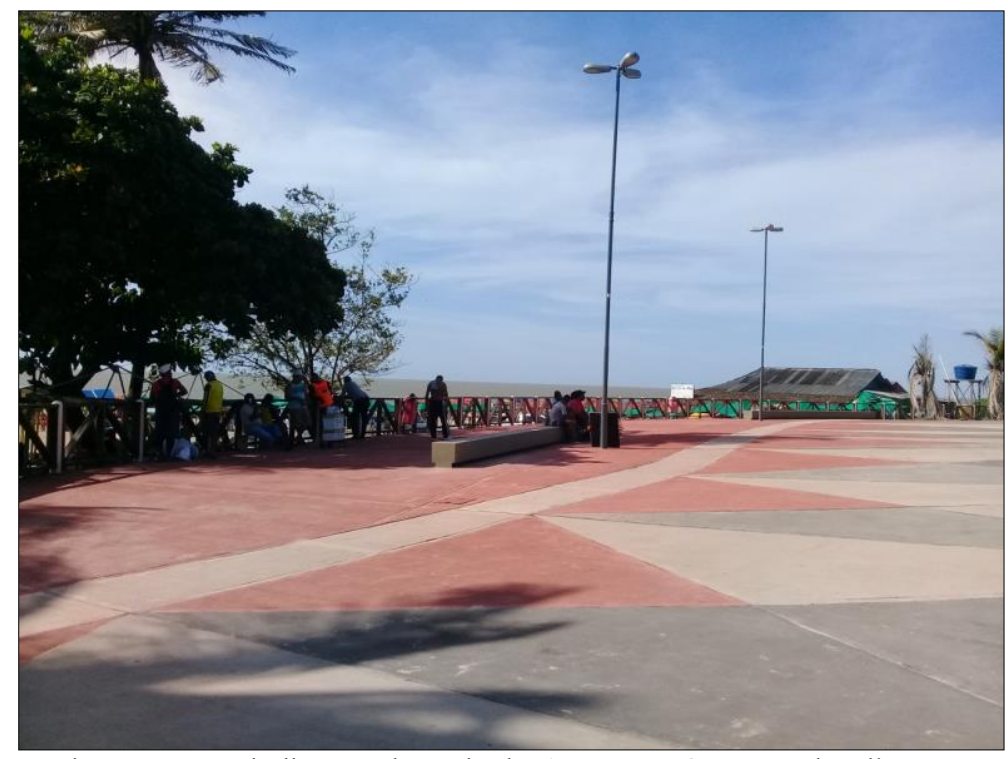

Figura 9 - Revitalização da praia do Araçagy - São Jose de Ribamar.

Fonte: Registro dos autores, 2018. 
|Práticas marítimas modernas no município de São José de Ribamar - MA: ações e transformações que impulsionam o turismo local|

|Jacilene dos Santos Castro | Audivan Ribeiro Garcês Júnior | Paulo Roberto Mendes Pereira | |Eustógio Wanderley Correia Dantas |

São José de Ribamar também possui praias semidesertas, com paisagens naturais e um roteiro ideal para quem quer relaxar ou se aventurar em acampamentos e ecoturismo. As praias de Boa Viagem (Figura 10) e Juçatuba são mais isoladas, com paisagens naturais e casas de veraneios disponíveis para locação, ideais para a prática do turismo ecológico, acessíveis por transporte particular ou transporte público.

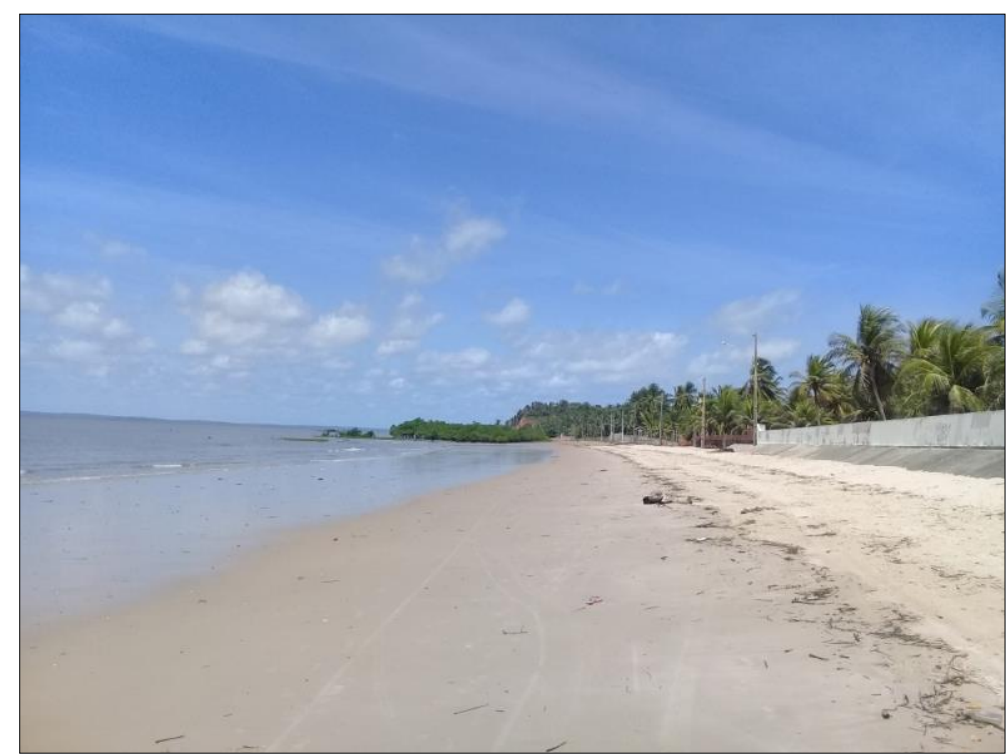

Figura 10 - Praia de Boa Viagem - São Jose de Ribamar. Fonte: Registro dos autores, 2018.

Boa Viagem se apresenta como um lugar bucólico, pois o que se encontra são algumas unidades de pescadores em alto mar e casas de veraneio esquecidas.

A praia de Juçatuba caracteriza-se pela vista privilegiada da Baía de São José e da cidade de São José de Ribamar. Conhecida também por praia de Unicamping (Figura 11), nome dado em referência aos primeiros desbravadores do lugar, pessoas que se deslocavam para acampar na chamada ilha deserta. A faixa de areia tem cerca de 800 metros de extensão e a praia é cercada pelo mangue. 
| Práticas marítimas modernas no município de São José de Ribamar - MA: ações e transformações que impulsionam o turismo local|

|Jacilene dos Santos Castro | Audivan Ribeiro Garcês Júnior | Paulo Roberto Mendes Pereira | |Eustógio Wanderley Correia Dantas |

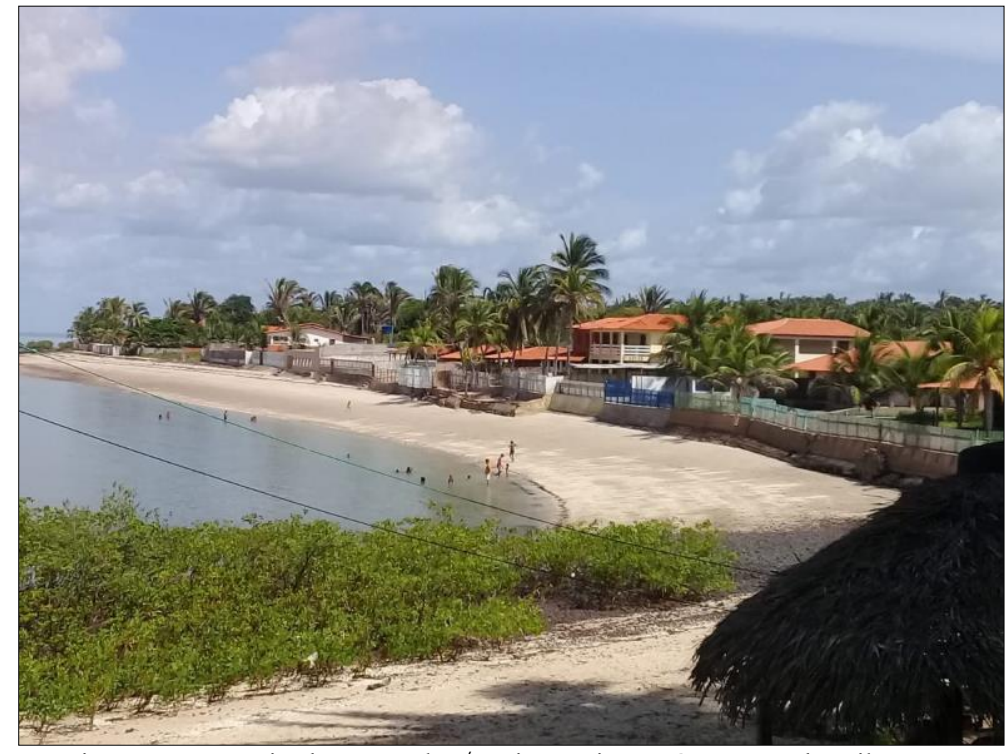

Figura 11 - Praia de Juçatuba/Unicamping - São Jose de Ribamar.

Fonte: Registro dos autores, 2018.

Caúra e Ponta Verde são praias formadas por falésias, propícias para esportes náuticos e com casas de veraneio, disponibilizadas para aluguel. O estirâncio da praia de Caúra (Figura 12) é utilizado pelos visitantes para a prática de esportes e para a instalação de barracas pelos donos de bares nos períodos de maior visitação, geralmente durante as festividades do município (SOUZA; CAMPOS; FEITOSA, 2007). O acesso à praia do Caúra é realizado por embarcações ou por terra, alguns dos esportes náuticos praticados na praia são caiaque e stand up paddle.

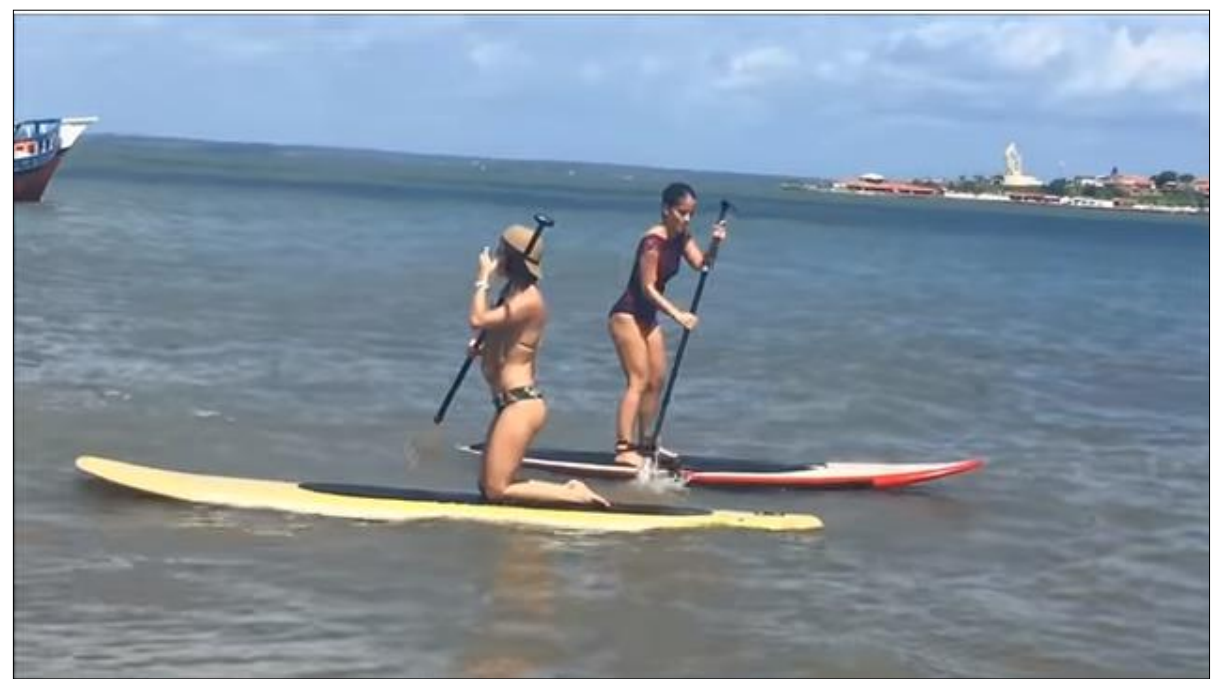

Figura 12 - Stand up paddle, praia do Caúra - São Jose de Ribamar Fonte: Prefeitura de São José de Ribamar, 2017.

Segundo Souza, Campos e Feitosa (2007), os pescadores que moram na região, transportam passageiros nos períodos em que não estão pescando, geralmente são turistas, 
| Práticas marítimas modernas no município de São José de Ribamar - MA: ações e transformações que impulsionam o turismo local|

|Jacilene dos Santos Castro | Audivan Ribeiro Garcês Júnior | Paulo Roberto Mendes Pereira| |Eustógio Wanderley Correia Dantas |

visitantes e moradores da praia que vêm à sede do município para trabalhar, estudar ou em busca de serviços bancários e de bens alimentícios, visto que esta é a forma mais simples de se conseguir estes tipos de serviços.

Além das práticas marítimas modernas já citadas, existe no município um festival destinado a um de seus principais produtores de renda, o pescado. O consumo da espécie de pescado denominada "peixe-pedra" se tornou salutar no município, devido esse peixe ser encontrado em grande quantidade na baía de São José. Foi, então, criado o Festival do Peixe-Pedra em 1977, na tentativa de atrair turistas e movimentar a economia local, conforme os relatos históricos. O evento era organizado pela Prefeitura Municipal, com o apoio da Colônia de Pescadores e Associação dos Barqueiros, a programação cultural era desenvolvida nas dependências do Parque Municipal Folclórico Therezinha Jansen, situado na orla marítima da cidade, onde também eram instaladas dezenas de barracas, nas quais os visitantes podiam apreciar as diversas formas de consumir o peixe-pedra.

O Festival do Peixe-Pedra contava com uma programação cultural, gastronômica e esportiva, com a tradicional regata marítima (Figura 13), cujos navegadores partiram da praia de Guarapiranga em direção à praia de Banho, na sede do município, em uma competição da pesca do maior peixe-pedra, assim como o Circuito Maranhense de Vôlei de Praia, com jogos entre duplas com premiação para as melhores colocações das competições, além de shows e atrações culturais.

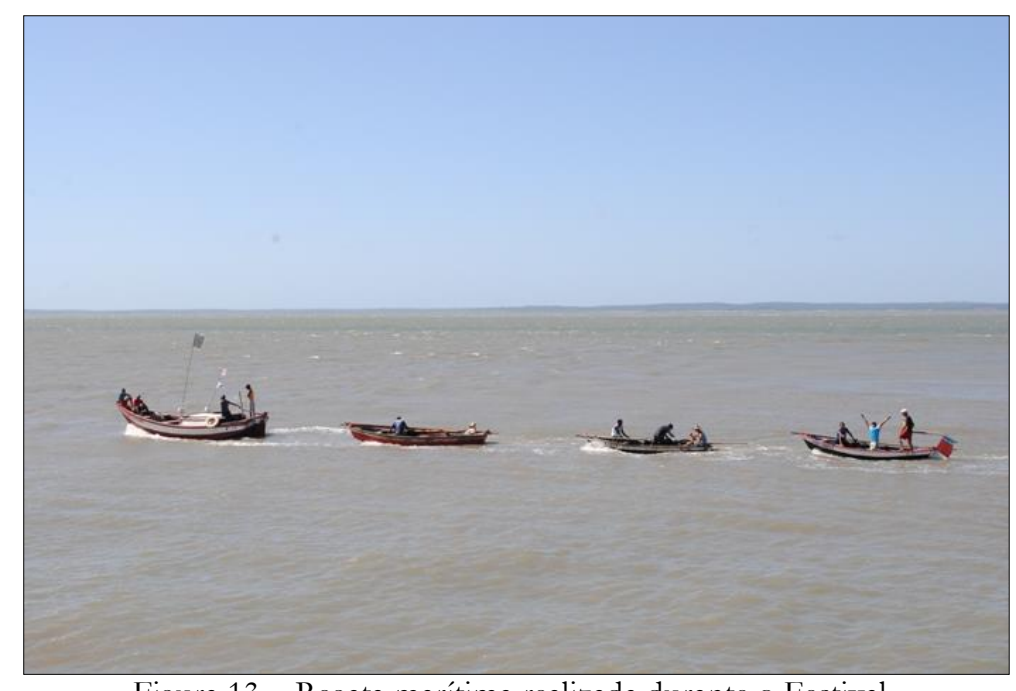

Figura 13 - Regata marítima realizada durante o Festival. Fonte: Prefeitura de São José De Ribamar, 2011.

Segundo Conceição (2008), na década de 1990, sua realização foi interrompida, sendo retomada somente em 2005 e chegando em 2011 com a sua 21a edição. Porém, nos últimos três anos, segundo a SEMTUC - Secretaria Municipal de Turismo e Cultura, o 
|Práticas marítimas modernas no município de São José de Ribamar - MA: ações e transformações que impulsionam o turismo local|

|Jacilene dos Santos Castro | Audivan Ribeiro Garcês Júnior | Paulo Roberto Mendes Pereira| |Eustógio Wanderley Correia Dantas |

festival deixou de acontecer, por desacordos entre os organizadores e hoje está sendo reformulado para atrair maior número de turistas.

Atualmente um dos principais cartões postais da cidade é o Cais de Ribamar, revitalizado em 2017. Com a revitalização, o cais ganhou equipamentos para o lazer e ginásticas (Figura 14), uma estrutura que conta com áreas de passeio e convivência e diversificação da oferta turística e de lazer no município.

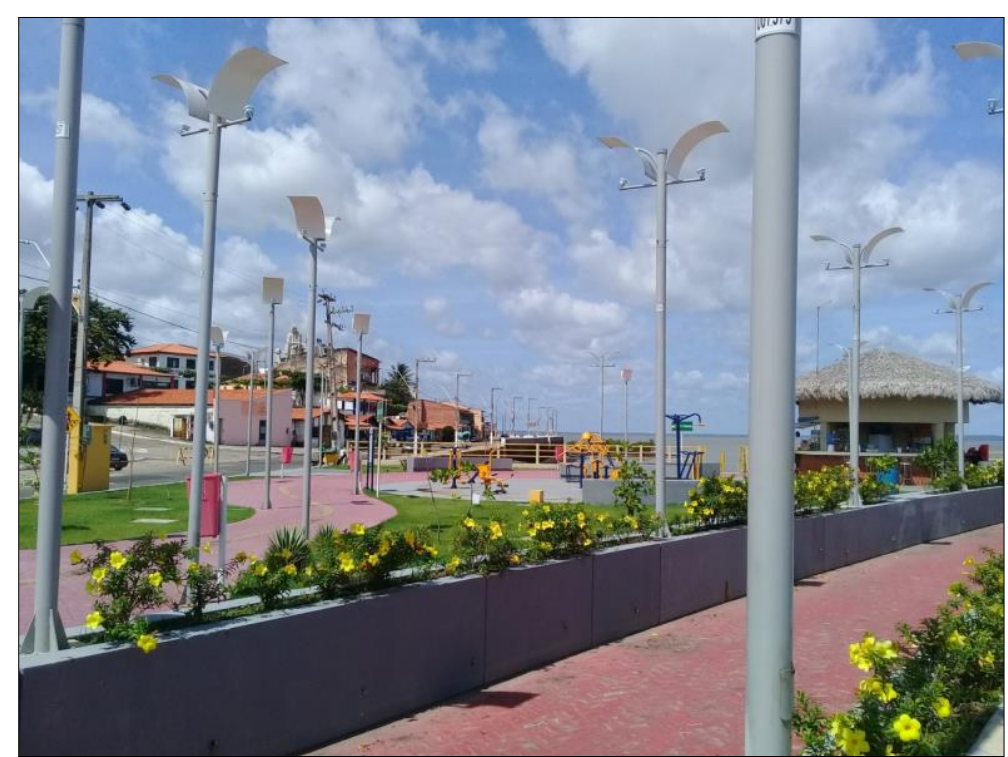

Figura 14 - Área de lazer do Cais de Ribamar - São José de Ribamar.

Fonte: Registro dos autores, 2018.

Com esse novo investimento no espaço litorâneo, a população vem se apropriando através do lazer ou pela oportunidade de geração de renda, com a venda de produtos artesanais ou alimentos. O local conta também com um posto policial, que gera uma sensação de segurança para as famílias ribamarenses e para os visitantes. O novo cais tem em seus objetivos atender às pequenas embarcações da região e ao mesmo tempo fomentar o turismo local.

Ao esmiuçar as práticas marítimas modernas incorporadas ao litoral ribamarense, percebemos que o mesmo busca alcançar todo o público que procura lazer e turismo em lugares marítimos. Para tanto, vem se adaptando de acordo com a realidade do local e a necessidade de quem o usufrui. Em certos lugares não é preciso haver transformações, revitalizações, modernizações, basta existir o olhar curioso de quem pretende o apreender. No entanto, é necessário que haja o planejamento das ações voltadas para o turismo, a fim de que realmente as atividades deste setor possam propiciar a geração de renda à população e ao município, bem como para que a atividade não desencadeie outros problemas para os locais visitais, haja vista a vulnerabilidade dos ambientes marítimos às atividades antrópicas. 
|Práticas marítimas modernas no município de São José de Ribamar - MA: ações e transformações que impulsionam o turismo local|

|Jacilene dos Santos Castro | Audivan Ribeiro Garcês Júnior | Paulo Roberto Mendes Pereira| | Eustógio Wanderley Correia Dantas |

\title{
PLANEJAMENTO TURÍSTICO: uma alternativa para o desenvolvimento sustentável
}

Sabe-se que os efeitos do turismo não se processam de forma idêntica em todos os destinos ou para todas as pessoas envolvidas, pois implicam em determinadas especificidades. No entanto, pode-se afirmar que a atividade turística causa impactos de várias ordens, cabendo ao planejamento com base em premissas de sustentabilidade a tarefa de maximizar os benefícios e minimizar os custos, sejam eles econômicos, sociais, ambientais ou culturais.

Para Machado (1998, p. 35), o planejamento turístico constitui uma "sistematização de ações previstas, a partir de uma análise da realidade onde se quer atuar, com o objetivo de desenvolver o potencial turístico de uma determinada localidade”. Assim, as políticas públicas do turismo são recursos que devem ser utilizados para que a atividade turística seja planejada de forma coerente e eficaz, quando se diz respeito à busca do desenvolvimento local sustentável a partir da mesma.

Nessa perspectiva, entende-se que o desenvolvimento sustentável do turismo deveria estar centrado no ser humano e no ambiente, como aponta Fonteles:

\begin{abstract}
Assim, evitar-se-ia a manipulação exagerada das pessoas e contribuir-se-ia para um crescimento ecologicamente equilibrado e sustentável, entendendo por sustentabilidade não apenas o aspecto econômico, mas também o político, social, e o cultural, destacando a população como elemento indispensável (FONTELES, 2004, p. 205).
\end{abstract}

Para evitar que o turismo se autodestrua, seria necessário planejá-lo estrategicamente, envolvendo os atores ligados diretamente com o setor: o poder público, iniciativa privada e comunidade receptora, onde a relação custo/benefício não seja pautada exclusivamente nos aspectos econômicos, mas também socioculturais. Como explica Fonteles (2004, p. 208), "seria interessante que essas populações fossem envolvidas no processo desde o planejamento, passando pela execução e avaliação do impacto que o turismo traz a sua comunidade".

A opinião dos moradores a respeito do turismo torna-se indispensável para o planejamento adequado em uma localidade turística. Aqueles membros da população anfitriã que são influenciados pelo comportamento dos turistas, provavelmente influenciarão outros membros de sua comunidade com suas atitudes e comportamento 
|Práticas marítimas modernas no município de São José de Ribamar - MA: ações e transformações que impulsionam o turismo local|

|Jacilene dos Santos Castro | Audivan Ribeiro Garcês Júnior | Paulo Roberto Mendes Pereira| | Eustógio Wanderley Correia Dantas |

modificados, fazendo com que o fenômeno se torne desejável ou indesejável pela população em geral.

O Plano Diretor de São José de Ribamar (2006) dispõe de objetivos políticos, sociais, econômicos, físico-ambientais e administrativos que orientarão o desenvolvimento do município. Destaque aos propósitos que são direcionados ao turismo: promover o desenvolvimento do turismo local; promoção do desenvolvimento econômico e do turismo, de forma a preservar os recursos e potencialidades ambientais; incentivar o turismo; melhoria da receita e arrecadação municipal, principalmente no setor de serviço e do turismo e estímulo à implantação, desenvolvimento e manutenção do turismo. O Plano Diretor também nos traz as localidades onde as políticas de preservação e desenvolvimento devem ser aplicadas, destaque para as atividades relacionadas com o turismo litoral (Quadro 01):

Quadro 01 - Localidades e Ações Ambientais Prioritárias

\begin{tabular}{|c|c|c|}
\hline $\begin{array}{c}\text { Localidades, } \\
\text { Regiões e Recursos } \\
\text { Naturais }\end{array}$ & $\begin{array}{l}\text { Prioridade } \\
\text { Ambiental }\end{array}$ & Ações Recomendadas \\
\hline $\begin{array}{l}\text { Áreas voltadas para a } \\
\text { Baia de São José } \\
\text { Ponta Vermelha } \\
\text { Panaquatira } \\
\text { Praia do Banho } \\
\text { Praia de Boa Viagem } \\
\text { Praia de Juçatuba } \\
\text { Praia do Caúra } \\
\text { Praia de Ponta Verde }\end{array}$ & $\begin{array}{l}\text { Turismo ecológico } \\
\text { Esportes náuticos } \\
\text { Pesca } \\
\text { Turismo de veraneio } \\
\text { Transporte } \\
\text { Preservação da fauna }\end{array}$ & $\begin{array}{l}\text { Estruturar ancoradouros em Boa } \\
\text { Viagem, Caúra e uma marina na Sede, } \\
\text { para promover a integração por } \\
\text { transporte fluvial; promover o esporte } \\
\text { náutico compatível às condições } \\
\text { geoambientais locais (iatismo, esqui } \\
\text { aquático, navegação à vela em geral) } \\
\text { através de um calendário esportivo e } \\
\text { cultural e da divulgação dos eventos } \\
\text { nas instituições correlacionadas. } \\
\text { Organização das atividades comerciais } \\
\text { na orla em condições adequadas. }\end{array}$ \\
\hline
\end{tabular}

Fonte: Plano Diretor de São José de Ribamar, 2016.

Baseadas no Plano diretor e como exemplos de ações direcionadas para o incentivo da atividade turística, a Secretaria Municipal de Cultura e Turismo de São José de Ribamar menciona projetos que já foram concluídos e que estão sendo elaborados para o melhor desenvolvimento do turismo no município como: a revitalização do Cais; implantação de sinalização turística; realização de cursos de capacitação para quem trabalha no setor turístico, a exemplo o curso de capacitação para a formação de Agentes de Desenvolvimento Local e Oficinas de Empreendedores, em parceria com o SEBRAE; Programa Praia Legal é Praia Limpa, que tem como objetivo conscientizar a população 
|Práticas marítimas modernas no município de São José de Ribamar - MA: ações e transformações que impulsionam o turismo local|

|Jacilene dos Santos Castro | Audivan Ribeiro Garcês Júnior | Paulo Roberto Mendes Pereira| |Eustógio Wanderley Correia Dantas |

para o banho consciente e preservação à natureza; apoio a eventos diversos e ao turismo de negócios, dentre outros.

Acredita-se que, através de políticas de turismo precisas e eficientes, o setor passará a ser organizado de forma eficiente e dinâmica, no qual, segundo Bezerra (2003), o planejamento passa a ser coeso, levando-se em consideração a realidade e as características próprias de cada região, constituindo dessa forma, os fatores relevantes e imprescindíveis para que seja possível desenvolver a localidade a partir do turismo.

\section{CONSIDERAÇÕES FINAIS}

Estudar a maritimidade de um determinado lugar requer cuidados. Entender o modo como a mesma influenciou e influencia seu modo de vida é o primeiro passo. Ao adentrar no meio desse mar é preciso primeiramente fôlego para buscar em suas profundezas a origem de todo o seu processo, aproveitando o vai e vem da maré para buscar o máximo informações que concretizam sua fundamentação.

A maritimidade tem se tornado um assunto muito discutido, pois hoje o foco e os olhares de muitos interesses estão voltados para o mar. O litoral vem sendo pauta de diversos estudos, pois ele é um dos principais motores geradores da economia no Brasil. Aquele local de ócio vivenciado em tempos atrás, hoje, é passível de especulações turísticas, imobiliárias, disputas de espaços e de constantes transformações.

Percebe-se, então, uma disputa entre o tradicional e o moderno, um tentando se sobressair ao outro. A praia vem abrindo espaços para as práticas de lazer e turísticas ao passo que vai afastando de modo silencioso o pescador de seu habitat natural.

Não distante disso, temos o caso do município de São José de Ribamar, município com suas particularidades, porém com laços que os ligam e os tornam passíveis de análises: a apropriação do litoral como fonte de renda. Tradicionalmente sua economia e subsistência eram baseadas unicamente na pesca artesanal, atualmente, o litoral dispõe de ofertas que diversificam as atividades econômicas, abrindo espaços para novos meios de fonte de renda.

Transformações foram necessárias para que um novo litoral surgisse através do moldar do tempo. O que antes era somente local de moradia e trabalho, agora abre espaço para o lazer e turismo. O turismo litorâneo, principal impulsionador da modernização do litoral, trouxe consigo benefícios que modernizaram esses lugares: acesso às praias, asfaltamento, iluminação, áreas de lazer (praças), infraestrutura sanitária, instauração de 
| Práticas marítimas modernas no município de São José de Ribamar - MA: ações e transformações que impulsionam o turismo local|

|Jacilene dos Santos Castro | Audivan Ribeiro Garcês Júnior | Paulo Roberto Mendes Pereira| | Eustógio Wanderley Correia Dantas |

bares, pousadas e restaurantes, construção de casas de veraneios, ofertas de diferentes formas de esportes relacionadas ao mar, geração de emprego, dentre outros.

Porém, acabou por modificar a dinâmica dos que já viviam nesse lugar. Pescadores tradicionais são obrigados a se adaptar às novas práticas litorâneas e moradores passam a conviver com um fluxo de pessoas que não faziam parte de sua rotina. Esse modo de apropriação acaba trazendo novos atores para o litoral e afastando os antigos.

Litoral esse que, depois de modernizado, dificilmente será apropriado por inteiro por seus moradores, em sua maioria esses serviços e ofertas de apropriação se restringem somente aos visitantes e turistas. Ao morador resta servir como mão de obra para o turismo.

Outro aspecto importante no que tange às análises das práticas marítimas modernas em São José de Ribamar está relacionado à sistematização e planejamento do turismo utilizando as atividades citadas. Embora haja no plano diretor ênfase na temática, na prática, as ações voltadas para o turismo local ainda se dão de forma bastante lenta, com algumas ações pontuais, como a restauração de calçadões e urbanização do cais, assim, sendo necessária uma melhor estruturação desse segmento do município.

\section{REFERÊNCIAS}

ASCOM. Praias. Prefeitura de São José de Ribamar. 2017. Disponível em: $<$ http://www.saojosederibamar.ma.gov.br/detalhe-da-materia/info/praias/16540>.

Acesso em: 13 nov. 2017.

ASCOM. Turismo Cultural. Prefeitura de São José de Ribamar. 2017. Disponível em: $<$ http://www.sjr.ma.gov.br/detalhe-da-materia/info/turismo-cultural/16539>. Acesso em: 20 dez. 2017.

CONCEIÇÃO, M. de J. São José de Ribamar: cidade de encantos. 2. ed. ampliada. São Luís, MA: Gráfica e Editora Alpha, 2008.

COSTA, C. R. R. da. Planejamento e expansão do turismo no litoral do Maranhão. Conexões - Ciência e Tecnologia, Fortaleza/CE, v. 11, n. 5, p. 54-65, dez. 2017. Disponível em: < https://doi.org/10.21439/conexoes.v11i5.1290>. Acesso em: 20 dez. 2017.

COLTRO, Alex. A fenomenologia: um enfoque metodológico para além da modernidade. Caderno de Pesquisas em Administração, São Paulo, v. 1, n. 11, jan./mar. 2000.

DANTAS, E. W. C. Maritimidade nos trópicos: por uma geografia do litoral. 2. ed. Fortaleza: Edições UFC, 2010. 
| Práticas marítimas modernas no município de São José de Ribamar - MA: ações e transformações que impulsionam o turismo local|

|Jacilene dos Santos Castro | Audivan Ribeiro Garcês Júnior | Paulo Roberto Mendes Pereira | | Eustógio Wanderley Correia Dantas |

DE PAULA, E. O. Das práticas marítimas tradicionais às modernas: notas sobre a vilegiatura marítima na região metropolitana de Fortaleza. In: SEMINÁRIO NACIONAL GOVERNANÇA URBANA E DESENVOLVIMENTO METROPOLITANO, 2010, Natal. Anais... Natal: UFRN, 2010.

FONSECA, A. V. de L. Uma jornada geográfica litorânea como proposta para ensinar e aprender geografia na escola: uma experiência em São José de Ribamar-MA. 2013. Tese (Doutorado em Geografia) - Departamento de Geografia, Faculdade de Filosofia, Letras e Ciências Humanas, Universidade de São Paulo, São Paulo, 2013.

FONTELES, J. O. Turismo e impactos socioambientais. São Paulo: Aleph, 2004.

IBGE, Instituto Brasileiro de Geografia e Estatística. Censo Demográfico. Rio de Janeiro, IBGE, 2010.

IPEA, Instituto de Pesquisa Econômica Aplicada. Atlas da violência 2017. Rio de Janeiro, 2017.

MACHADO, G. M. F. Turismo Sustentável: uma alternativa de desenvolvimento para São José de Ribamar. 1998. Monografia (Graduação em Turismo) - Departamento de Turismo, Universidade Federal do Maranhão, São Luís, 1998.

SÃO JOSÉ DE RIBAMAR. Lei 645 de 10 de outubro de 2006, dispõe sobre o Plano Diretor do Município de São José de Ribamar - MA. 2006. Disponível em: <http://www.saojosederibamar.ma.gov.br/legislacao/sobre/>. Acesso em: 20 nov. 2018.

SOUZA, U. D. V.; CAMPOS NETO, J. R.; FEITOSA, A. C. A interface percepção ambiental e geomorfologia no estudo da praia de Caúra em São José de Ribamar - MA. Cadernos de Cultura e Ciência, v. 2, n. 2, p. 01-11, maio 2007. Disponível em: $<$ http://periodicos.urca.br/ojs/index.php/cadernos/article/view/120/81>. Acesso em: 30 dez. 2018. 